\title{
MANAGEMENT OF SHOULDER DISLOCATION BY PRAKASH METHOD
}

Ihsan Ullah ${ }^{1}$, Samir Khan Kabir², Khalid ${ }^{3}$, Mohammad Inam ${ }^{4}$, Gui Hassan ${ }^{5}$, Anwar-Ul-Haq Kiani ${ }^{6}$

\section{ABSTRACT:}

The objective of the study is to evaluate the effectiveness and safety of shoulder reduction developed by Prakash.

\section{METHODOLOGY:}

This descriptive study was carried out at Rehman Medical and Surgical Center District Buner and Naseer Teaching Hospital Peshawar from June 2017 to December 2019. All patients with a history of trauma to either shoulder were subjected to anterior-posterior shoulder radiograph. Those having shoulder dislocation were enrolled in the study. Data including age, gender, previous dislocation history, duration of dislocation and associated fracture, and fracture type were recorded in patient case sheet. Patients having recurrent dislocation, polytrauma, low GCS, fracture-dislocations, and more than a week history of dislocation were excluded from the study.

\section{RESULTS:}

This study was performed on 30 patients. The mean age of the patients was $36.46 \pm 11.58$ years. Among them, $83.3 \%(n=25)$ were male and $16.7 \%(n=5)$ were female. While dislocation occurred on the right shoulder in $63.3 \%(n=19)$ and in $36.7 \%(n=11)$ on the left side. All the patients have dislocation for the first time. The reduction was performed using Prakash 's method. The success rate was $90 \%(n=27)$ and $10 \%(n=3)$ the reduction failed, which was then reduced under anaesthesia using the Hippocratic method.

\section{CONCLUSION:}

The Prakash's method for reducing anterior shoulder dislocation requires minimum assistance with no anaesthesia, it is safe, less time consuming, has a high success rate, less pain, and has minimal complications

KEYWORDS: Dislocation, Glenohumeral Joint, Prakash's Method, Shoulder, Hippocratic Method

\section{How to cite this article:}

Ullah I, Kabir SK, Khalid, Inam M, Kiani UA. Management of Shoulder Dislocation by Prakash Method. J Gandhara Med Dent Sci. 2021;8(1): 21-24

https://doi.org/10.37762/jgmds.8-1.124

Correspondence

${ }^{1}$ Ihsan ullah, Medical Officer, $\mathrm{OHO}$ hospital Daggar, Buner. cell\# +92-333-9701552

email: khanihsan46@yaho.ocom

${ }^{2}$ Assistant Professor, Naseer Teaching Hospital,Peshawar

${ }^{3}$ Medical Officer, OHO hospital Daggar, Buner. ${ }^{4}$ Assistant

Professor, Lady Reading Hospital, Peshawar ${ }^{5}$ Associate

Professor, Kabir Medical College,Peshawar ${ }^{6}$ Registrar

Orthopedics, Princess Alexandra Hospital , Redditch,

Worcestershire, UK

\section{INTRODUCTION:}

Glenohumeral joint being one of the most mobile joints of the body; is much prone to dislocations $s^{1,6,10,13}$ when compared to other joints of the body. It accounts for about $50 \%$ of all joint's dislocation resenting to the emergency department ${ }^{2-5,8}$. In the general population, the incidence of shoulder dislocation is about $2-8 \%{ }^{1}$. Of all shoulder dislocations, the most common is anterior dislocation with an incidence of about $90-98 \%^{2,5,12,18,20}$. The dislocation occurs as a result of trauma or history of fall ${ }^{2-4,6,19}$. Shoulder dislocations are most often reduced closely for which more than 20 methods have been suggested ${ }^{13}$. The most used methods are Hippocratic or Kocher methods ${ }^{1,14}$. The success rate and complication vary according to the method used. Majority of dislocations are reduced with anesthesia ${ }^{11}$. The best method is the one, which requires minimum assistance, has a high success rate, requires no anesthesia, and is not time-consuming, has less pain, is safe, 
or has minimal complications ${ }^{1,3-5,7,9}$. The Hippocratic method or Kocher methods which being widely used has failed to yield the desired results and has a high complication rate ${ }^{8,14}$. Now a days there is a new method in vogue which has all these characteristics called the Prakash method. The Prakash method of reducing anterior shoulder dislocation, which requires minimum assistance, has a high success rate, requires no anaesthesia, and is not time-consuming, has less pain, is safe, or has minimal complications ${ }^{1,4}$. Accordingly, this study aims to evaluate the effectiveness and safety of shoulder reduction developed by Prakash method, which was carried in three hospitals of KPK from June 2017-December 2019.

\section{METHODOLOGY:}

This descriptive study was carried out at Rehman Medical and Surgical Centre District Buner from June 2017 to December 2019. All patients diagnosed with anterior shoulder dislocation by anterior-posterior shoulder radiograph were included in the study. Data including age, gender, previous dislocation history, duration of dislocation and associated fracture, and fracture type were recorded in patient case sheet. Patients excluded from the study were those having recurrent dislocation, polytrauma, unconscious patients (low GCS), more than one-week-old dislocation, and fracture-dislocations. After explaining the procedure, informed consent was taken from all patients. A total of 30 patients were initially enrolled. Data analysis was done for reduction success. A single attempt of reduction was done by Prakash's method. More than one attempt for reduction or reduction under anaesthesia was considered as failure of treatment. The same consultant did all reductions. The results were analysed using SPSS version 20 .

After explaining the procedure and taking written informed consent, patients were made to sit on the chair and scapular region supported against the chair. With one hand the surgeon holds the patient's wrist with other hand holding the patient elbows. Without any abduction or adduction gradual external rotation of the shoulder is done making it parallel to the coronal plane. Maintaining external rotation for more than a minute and the surgeon tries to alleviate patient apprehension by engaging him in some talk. In the same position adducting the arm gradually until the elbow rests over the body with gradualinternal rotation of the arm so that the hand touches the opposite shoulder. The shoulder will get reduced without any clunk or sound.

This study was performed on 30 patients. The mean age of the patients was $36.46 \pm 11.58$ years. Among them, 83.3\% $(n=25)$ were male and $16.7 \% \quad(n=5)$ were female. While dislocation occurred on the right shoulder in $63.3 \%(n=19)$ and in $36.7 \%(n=11)$ on the left side. All the patients have dislocation for the first time. Reduction was performed using Prakash's method. The success rate was $90 \%$ $(n=27)$. In 10\% ( $n=3)$ the reduction failed who were then reduced under anaesthesia using the Hippocratic method.

Table 1: Demographics and Reduction Data

\begin{tabular}{|l|c|c|}
\hline $\begin{array}{l}\text { Age (Years) } \\
\text { Mean } \pm \text { SD }\end{array}$ & \multicolumn{2}{|c|}{$36.46 \pm 11.58$} \\
\hline Gender & $\begin{array}{c}\text { Male } \\
\text { N (\%) }\end{array}$ & $\begin{array}{c}\text { Female } \\
\text { N (\%) }\end{array}$ \\
\cline { 2 - 3 } & $\begin{array}{c}25 \\
(83.3 \%)\end{array}$ & $5(16.7 \%)$ \\
\hline Affected Side & $\begin{array}{l}\text { Right } \\
\text { N (\%) }\end{array}$ & Left \\
& $1 \%)$ \\
\cline { 2 - 3 } & $193.3 \%)$ & $(36.7 \%)$ \\
\hline $\begin{array}{l}\text { Reduction Success } \\
\text { Rate- N(\%) }\end{array}$ & \multicolumn{2}{|c|}{$27(90 \%)$} \\
\hline $\begin{array}{l}\text { Reduction Failure } \\
\text { Rate- N(\%) }\end{array}$ & \multicolumn{2}{|c|}{$3(10 \%)$} \\
\hline
\end{tabular}

\section{DISCUSSION:}

The glenohumeral joint is one of the most mobile joints of the body movable in all directions. The relatively small glenoid fossa with a large humeralhead makes it much prone to dislocation. In whichthe anterior dislocation is more common

Different physicians have suggested different methods of close reduction for shoulder dislocation. Nowadays Prakash's method is introduced for the reduction. In 2018, Prakash managed 147 patients of anterior shoulder dislocation with a $100 \%$ success rate without any 
complication ${ }^{4}$, while success rate in the current study was $90 \%$ with no complications. In 2019 a study by Anjum et al, ${ }^{8}$ using Prakash's maneuver for anterior shoulder dislocation reported a success rate of $95.08 \%$ on the first attempt, which is almost comparable to the current study. In the same study 61 patients with 58 dislocations were reduced with the first attempt having a success rate of $95.08 \%$ while the remaining 3 patients were relocated by the same maneuvers in the second attempt. They reported no complication related to the procedure ${ }^{8}$. In the current year, Kuru et al reduced 18 shoulders out of 19 with a success rate of $94.7 \%$ without any complication using Prakash's method of shoulder dislocation ${ }^{1}$. In our study, we included 30 patients of anterior shoulder dislocation relocated by Prakash's method. Out of which 27 patients were successfully reduced having a success rate of $90 \%$. Three patients were unable to reduce with Prakash's method, which was tried with the Hippocratic method leading to a failure rate of $10 \%$. No complication was reported in our study related to Prakash's method.

\section{CONCLUSION:}

Anterior shoulder dislocation is more common due to the disproportionate size of the head of humorous as compared to the glenoid cavity. Many methods are used to relocate the shoulder, none is without complication.

\section{LIMITATIONS:}

The sample size of this study was small. To reduce further complications it is important to carry out more research on a shoulder joint dislocation by Prakash method.

\section{RECOMMENDATIONS:}

This method is easy to administer and without prior preparation of the patient. Orthopedics and trauma surgeons should try Prakash's method in the emergency room for anterior shoulder dislocation, as it is cost effective.

CONFLICT OF INTEREST: None

FUNDNG SOURCES: None

\section{REFERENCES:}

1. Kuru T, Olcar HA, Bilge A, Nusran G, Ozkilic R, Akman C, et al. No sedation, no traction, and no need for assistance: analysis of new Prakash's method of shoulder reduction. Emerg Med Int. 2020;2020:1-5.

2. Theivendran K, Thakrar RR, Deshmukh SC, Dwan K. Closed reduction methods for acute anterior shoulder dislocation. Cochrane Database Syst Rev. 2019;2019(1):CD011051.

3. Marinelli $M$, de Palma $L$. The external rotation method for reduction of acute anterior shoulder dislocations. J Orthopaed Traumatol. 2009;10(1):17-20.

4. Prakash L. A new method for reduction of shoulder dislocations. Ortho Surg Ortho Care Int J. 2018;1(3):1-5.

5. Chung $\mathrm{CH}$. Closed reduction techniques for acute anterior shoulder dislocation: from Egyptians to Australians . Hong KongJ Emerg Med. 2004;11(3):178-88.

6. Cutts $S$, Prempeh M, Drew S. Anterior Engl. 2009;91(1):2-7.

7. Yuen MC, Yap PG, Chan YT, Tung WK. An easy method to reduce anterior shoulder dislocation: the Spaso technique. Emerg Med J. 2001;18(5):370-2.

8. Anjum R, Pathak S, Sharma AR, Aggarwal $J$, Sharma A, Pruthi V, et al. Reducing shoulder dislocation without anaesthesia or assistant: validation of a new reduction manoeuvre. Chin J Traumatol. 2019;22(5):274-7.

9. Stafylakis D, Abrassart S, Hoffmeyer P. Reducing a shoulder dislocation without sweating. The Davos technique and its results. Evaluation of a nontraumatic , safe, and simple technique for reducing anterior shoulder dislocations. J Emerg Med. 2016;50(4):656-9.

10. Lo H, Shen PY, Shen PC, Chou PH, Lu CC. The elbow technique: a novel reduction technique for anterior shoulder dislocations. J Emerg Med. 2019;56(2):201-4 .

11. Adhikari S, Koirala P, Katie D. Comparison of scapular manipulation with external rotation method of reduction of 
acute anterior shoulder dislocation for sedation requirements and success rates. J Spec Oper Med. 2018;18(3):34-7.

12. Orbach $H$, Rozen $N$, Rubin $G$. New technique for reduction of irreducible anterior glenohumeral shoulder dislocation. J Int Med Res. 2018;48(3): 15.

13. Akcimen M, Bedel C. Comparison between new modified external rotation method and external rotation method for reduction of ASD. Am $J$ Emerg Med. 2020;38(5):874-8.

14. Dala-Ali B, Penna M, McConnell J, Vanhegan I, Cobiella C. Management of acute anterior shoulder dislocation. $\mathrm{Br} J$ Sports Med. 2014;48(16):1209-15.

15. Shah AS, Karadsheh MS, Sekiya JK. Failure of operative treatment for glenohumeral instability: etiology and management. Arthroscopy: Arthroscopic Related Surg. 2011;27(5):681-94.
16. Adams F. The internet classics archive: instruments of reduction by Hippocrates. 2003. Available from:

http://classics.mit.edu/

Hippocrates/reduct.5.5.html

17. Regauer M, Polzer H, Mutschler W. Neurovascular complications due to the Hippocrates method for reducing anterior shoulder dislocations. World J Orthop. 2014;5(1):57-61.

18. Eshoj HR, Rasmussen S, Frich LH, Hvass I, Christensen R, Boyle $\mathrm{E}$, et al. Neuromuscular exercises improve shoulder function more than standard care exercises in patients with a traumaticanterior shoulder dislocation: a randomized controlled trial. Orthop J Sports Med. 2020;8(1):1-12.

19. Olds MK, Ellis R, Parmar $P$, Kersten $P$. Who will redislocate his/her shoulder? predicting recurrent instability following a first traumatic anterior shoulder dislocation. BMJ Open Sport Exercise Med. 2019;5(1):e000447.

\section{CONTRIBUTORS}

1. Ihsan Ullah - Concept \& Design; Data Acquisition; Data Analysis/Interpretation; Drafting Manuscript; Critical Revision

2. Samir Khan Kabir - Concept \& Design; Data Acquisition; Critical Revision; Supervision; Final Approval

3. Khalid - Data Acquisition; Data Analysis/Interpretation

4. Mohammad Inam - Data Acquisition; Data Analysis/Interpretation; Drafting Manuscript; Critical Revision

5. Gui Hassan - Critical Revision; Supervision; Final Approval

6. Anwar-UI-Haq Kiani- Drafting Manuscript; Critical Revision; Supervision; Final Approval

\section{(c) (1) (2)(2)}

$$
\begin{aligned}
& \text { LICENSE: JGMDS publishes its articles under a Creative Commons Attribution Non-Commercial Share-Alike license (CC-BY-NC-SA 4.0). } \\
& \text { COPYRIGHTS: Authors retain the rights without any restrictions to freely download, print, share and disseminate the article for any lawful } \\
& \text { purpose. It includes scholarly networks such as Research Gate, Google Scholar, LinkedIn, Academia.edu, Twitter, and other academic or } \\
& \text { professional networking sites. }
\end{aligned}
$$

